\title{
Reliability of mobility measures in older medical patients with cognitive impairment
}

\author{
Tobias Braun $^{1 *}$ (D), Christian Thiel ${ }^{1,2}$ (D), Ralf-Joachim Schulz ${ }^{3}$ and Christian Grüneberg ${ }^{1}$ (D)
}

\begin{abstract}
Background: Mobility is a key indicator of physical functioning in older people, but there is limited evidence of the reliability of mobility measures in older people with cognitive impairment. This study aimed to examine the test-retest reliability and measurement error of common measurement instruments of mobility and physical functioning in older patients with dementia, delirium or other cognitive impairment.
\end{abstract}

Methods: A cross-sectional study was performed in a geriatric hospital. Older acute medical patients with cognitive impairment, indicated by a Mini-Mental State Examination (MMSE) score of $\leq 24$ points, were assessed twice within 1 day by a trained physiotherapist.

The following instruments were applied: de Morton Mobility Index, Hierarchical Assessment of Balance and Mobility, Performance-Oriented Mobility Assessment, Short Physical Performance Battery, 4-m gait speed, 5-times chair rise test, 2-min walk test, timed up and go test, Barthel Index mobility subscale and Functional Ambulation Categories. As appropriate, the intraclass correlation coefficient (ICC), Cohen's kappa, standard error of measurement, limits of agreement and minimal detectable change (MDC) values were estimated.

Results: Sixty-five older acute medical patients with cognitive impairment participated in the study (mean age: $82 \pm 7$ years; mean MMSE: $20 \pm 4$, range: 10 to 24 points). Some participants were physically or cognitively unable to perform the gait speed (46\%), 2-min walk (46\%), timed up and go (51\%) and chair rise (75\%) tests. ICC and kappa values were above 0.9 in all instruments except for the gait speed $($ ICC $=0.86)$ and chair rise $(I C C=0.72)$ measures. Measurement error is reported for each instrument. The absolute limits of agreement ranged from 11\% (de Morton Mobility Index and Hierarchical Assessment of Balance and Mobility) to 35\% (chair rise test).

Conclusions: The test-retest reliability is sufficient (>0.7) for group-comparisons in all examined instruments. Most mobility measurements have limited use for individual monitoring of mobility over time in older hospital patients with cognitive impairment because of the large measurement error (> 20\% of scale width), even though relative reliability estimations seem sufficient $(>0.9)$ for this purpose.

Trial registration: German Clinical Trials Register (DRKS00005591). Registered 2 February 2015.

Keywords: Older people, Mobility limitation, Dementia, Cognitive impairment, Outcome measure, Reliability, Measurement error, Minimal detectable change, Limits of agreement

\footnotetext{
* Correspondence: tobias.braun@hs-gesundheit.de

'Department of Applied Health Sciences, Division of Physiotherapy,

Hochschule für Gesundheit (University of Applied Sciences),

Gesundheitscampus 6-8, 44801 Bochum, Germany

Full list of author information is available at the end of the article
}

(c) The Author(s). 2019 Open Access This article is distributed under the terms of the Creative Commons Attribution 4.0 International License (http://creativecommons.org/licenses/by/4.0/), which permits unrestricted use, distribution, and reproduction in any medium, provided you give appropriate credit to the original author(s) and the source, provide a link to the Creative Commons license, and indicate if changes were made. The Creative Commons Public Domain Dedication waiver (http://creativecommons.org/publicdomain/zero/1.0/) applies to the data made available in this article, unless otherwise stated. 


\section{Background}

Aside from providing life-supporting interventions, the goal of hospital care and rehabilitation for older people with critical illness is to improve or preserve their health, functional independence and quality of life. Mobility and physical functioning are crucial health-related outcomes, which have an impact on this goal. Mobility is defined in the World Health Organisation's International Classification of Functioning, Disability and Health (ICF) as "moving by changing body position or location or by transferring from one place to another, by carrying, moving or manipulating objects, by walking, running or climbing, and by using various forms of transportation" [1]. Mobility is a key indicator of physical functioning in older people, and common measures of mobility, such as gait speed or the timed up and go test (TUG), are used to assess these outcomes.

To monitor alterations in mobility, clinicians depend on reliable measurement instruments to provide trustworthy test scores over time (change scores). To differentiate real change from measurement error, sound evidence on the extent of the latter must be available. Test-retest reliability (relative reliability) concerns the extent to which scores of patients who have not changed are the same for repeated measurement over time [2]. Classic measurement theory assumes that every measurement, or obtained score, consists of a true component and an error component, and all variability within a person's score is viewed as measurement error [3]. Possible facets of variability in repeated test scores can be instrumented-based, rater-based or subject-based (biological variability) [3]. Thus, measurement error (absolute reliability) is the systematic and random error of a patient's score that is not attributed to true changes in the construct to be measured [2]. Parameters of measurement error are the standard error of measurement, the limits of agreement proposed by Bland and Altman, and the minimal detectable change (MDC) $[2,4,5]$. The $\mathrm{MDC}$ is defined as a change beyond measurement error; it "represents the spread of the distribution of change scores that would be expected if no true change had occurred" [4].

A significant proportion of older hospital patients presents with cognitive impairment, which typically results from chronic conditions (e.g. dementia) or temporal syndromes (e.g. delirium). The in-hospital prevalence for dementia is estimated to be between 13 and 63\% [6]. Approximately 20 to $27 \%$ of older acute patients present with delirium $[7,8]$. Obtaining reliable performance-based test scores from older people with dementia can be challenging [9-11]. Proposed requirements include the ability to comprehend test commands, the ability to develop an adequate motor action and sequence, the ability to recollect both during execution, as well as the patient's adequate motivation and attention during testing [9]. Especially in acute medical patients with dementia, delirium or other cognitive impairment, these requirements may vary over time and influence the within-subject variance of the test performance.

Limited information exists on the reliability of mobility measures in older people with dementia, delirium or other cognitive impairment $[12,13]$. The methodological quality of the few, mostly small-scale studies varies, and for the most commonly used instruments, there is conflicting evidence on test-retest reliability. By way of example, for the TUG, intraclass correlation coefficients (ICCs) between 0.56 and 0.96 have been reported [11, 14-17]. Test-retest reliability estimates also vary considerably for gait speed measures ( $\mathrm{ICC}=0.57$ to 0.97 ) [16-19], and timed chair rise tests ( $\mathrm{ICC}=0.80$ to 0.97 ) $[15,17,20-22]$. Reliability estimates of such single-component mobility instruments are based on studies performed with older communitydwelling (outpatient) people or nursing-home residents with cognitive impairment.

For multicomponent instruments, which are considered more construct valid and applicable in the hospital setting [23, 24], such as the Hierarchical Assessment of Balance and Mobility (HABAM) [25], the Short Physical Performance Battery (SPPB) [26], Tinetti's Performance Oriented Mobility Assessment (POMA) and the de Morton Mobility Index (DEMMI) [27], evidence on test-retest reliability in older hospital patients with cognitive impairment has not yet been established.

We have recently examined the psychometric properties of the DEMMI in older individuals with dementia, delirium or other cognitive impairment, providing first evidence for the DEMMI to be a feasible, unidimensional and construct valid measurement instrument of mobility in this population [28]. Since we have not analysed reliability in this study, the main objective of the present study was to examine the test-retest reliability of the DEMMI. Given the lack of evidence on the reliability of mobility measures in older people with cognitive impairment, the secondary objective was to examine the test-retest reliability of several other commonly used measures of mobility in older acute medical patients with dementia, delirium or other cognitive impairment based on the available data set.

\section{Methods}

\section{Design and setting}

This cross-sectional study is a sub-analysis of the reliability data generated in a primary study on the psychometric properties of the DEMMI in a consecutive sample of older acute medical patients with cognitive impairment [28]. The primary study was approved by the Ethical Review Board of the University of Cologne (registration number 2014-05), conducted according to 
the ethical principles of the Declaration of Helsinki (2013), a priori registered in the German Clinical Trials Register (DRKS00005591) and performed in a geriatric hospital in Cologne, Germany. All participants provided ongoing, written informed consent. Additional guardian informed consent was obtained for every participant with a legal representative and for every participant considered to have limited capability to understand the study procedures. The latter was determined by a consortium composed of the ward physician, the primary nurse and the relatives, if appropriate. Proposed recommendations of the STrengthening the Reporting of Observational studies in Epidemiology (STROBE) statement for cross-sectional studies as well as the Guidelines for Reporting Reliability and Agreement Studies (GRRAS) were followed [29, 30].

Participants with cognitive impairment included in the primary study were assessed with a comprehensive set of mobility measures immediately after hospital admission (baseline sample). To assess test-retest reliability, all baseline mobility measures were repeated in a sub-sample of the baseline sample participants. The present study reports the test-retest reliability and measurement error of commonly used measurement instruments of mobility and physical functioning, including the corresponding subscales.

\section{Participants}

Participant enrolment was from 4 February to 11 December 2015. We defined 91 screening days, which were unsystematically spread across the study period. All acute geriatric inpatients consecutively admitted to the clinic on one of the screening days were screened for eligibility. A sample of 153 patients was included and constituted the baseline sample of the primary study [28].

Patients were eligible if they were admitted to one of the acute geriatric wards of the hospital, $\geq 60$ years old and presented with cognitive impairment as indicated by a Mini-Mental State Examination (MMSE) score of $\leq 24$ points [31]. Exclusion criteria were: documented contraindications for mobilisation, physician-directed partial weight-bearing of the lower extremity, isolation for infection, impending death, coma or severely impaired vigilance, acute major organ failure, blindness, deafness, severe dysphasia, German language barrier, or any acute psychiatric or medical/physical condition whereby mobility measurements could lead to a worsening of the health state.

\section{Procedures}

Eligible participants were examined within 7 days after hospital admission by the primary investigator (TB), a physiotherapist with 7 years of clinical and academic working experience who was well trained in the administration of the measurement instruments (has used each instrument in more than 200 cases prior to this study). In a single session, a comprehensive set of commonly used performance-based measurement instruments of mobility was administered in a standardised order, starting with the least physically challenging tests. Similar items in different assessments were only performed once to reduce participant's burden, e.g. standing with both feet together is required in the DEMMI and the Performance Oriented Mobility Assessment (POMA). In a sub-sample of eligible participants, all measures were repeated by the same assessor on the same day and in the same environment. The single independent rater was well informed of each participant's medical condition, such as diagnoses and level of cognitive impairment. The rater was not informed of the mobility capacity of each participant in detail (e.g. blinded towards routine physiotherapy outcome scores and walking aid use). In the retest session, the rater was not blinded towards the results of the first session.

A reliability analysis should be based on scores of patients whose medical condition has not changed (stable/ unchanged) [2]. In the present study, the baseline assessment session was usually performed in the morning, and the retest was usually done in the afternoon. Both assessment sessions were always administered on Saturdays. On weekdays, throughout the day, participants took part in a number of medical treatments and other interventions as part of usual care, making a change in the participants' physical and mental condition very likely (e.g. fatigue, pain, exhaustion or motor learning). On Saturdays, usual care therapy interventions were only applied to a small number of severely affected individuals in the study hospital. To explicitly include stable/unchanged participants, according to the definition of reliability [2], the intra-day retest assessment was only performed on participants assessed on Saturdays who did not participate in any diagnostic procedures or rehabilitation sessions (e.g. physical or occupational therapy) in between study assessments. Participants who reported any change in their physical or mental condition with respect to the first assessment (e.g. fatigue, pain or dizziness) were considered unstable and excluded. The nursing staff and the medical charts were consulted to validate the participants' perception of stability.

Socio-demographic data were taken from the medical records and from hospital administrative data. The MMSE [31], the Clock Drawing Test [32] and the 15-item short form of the Geriatric Depression Scale [33] were administered by the occupational therapy staff of the hospital as part of routine care. Diagnoses and medical symptoms that could be causal for the participants' cognitive impairment were extracted from the final hospital discharge reports. 


\section{Measurements}

In this study, 10 performance-based measures of the mobility capacity of older people were applied in the following order: DEMMI [27, 34], HABAM [35, 36], POMA [37], TUG [38], SPPB [39], 4-m gait speed (as part of the SPPB), 5-times chair rise test (5xCRT; as part of the SPPB), 2-min walk test [40], Barthel Index mobility subscale [41], and Functional Ambulation Categories (FAC) [42]. Additional file 1 provides a detailed description of the assessment procedures and all measurement instruments and their subscales.

Table 1 presents a clustered overview of the measurement instruments examined in this study according to the ICF mobility domain components captured by each instrument. According to this evaluation, instruments are separated into single-component and multi-component measures, depending on the number of mobility domains included. The classification in Table 1 is the consensus of the authors, informed by the classifications reported by other authors [24, 43].

\section{Statistical analysis}

Data were analysed using SPSS 21.0 (IBM Corp., Armonk, New York) and Microsoft Excel 2016 (Microsoft Office,
Redmond, Washington). Descriptive statistics were used to present sample characteristics. Statistical significance was set at $p<0.05$.

\section{Reliability \\ Test-retest reliability}

For all continuous outcomes, the relative intra-day test-retest reliability was examined using the intra-class correlation coefficient model 2.1 (two-way random effects model; ICC $_{\text {AGREEMENT }}$ ) [4]. The ICC AGREEMENT $_{\text {a }}$ walculated by dividing the systematic differences between the "true" scores of patients by the error variance, which consists of the systematic differences between the true scores of patients, the variance due to systematic differences between the two measurements, and the residual variance [4]. For the categorial outcome FAC, we determined the relative test-retest reliability using a weighted kappa with linear weights [4]. ICC and $K \geq 0.7$ were deemed acceptable for group-comparisons, whereas ICC and $\mathrm{K} \geq 0.9$ were deemed acceptable for individual measurements over time $[44,45]$. The test-retest reliability was additionally examined for sub-groups by gender.

Table 1 Mobility domain components of each measurement instrument classified according to the ICF

\begin{tabular}{|c|c|c|c|c|c|c|c|c|c|c|c|}
\hline \multirow{2}{*}{\multicolumn{2}{|c|}{ Domain components }} & \multicolumn{6}{|c|}{ Multi-component measurement instruments } & \multicolumn{4}{|c|}{ Single-component measurement instruments } \\
\hline & & DEMMI & HABAM & POMA & SPPB & TUG & $\begin{array}{l}\text { BI mobility } \\
\text { subscale }\end{array}$ & FAC & Gait speed & $5 \times C R T$ & $2 \mathrm{minWT}$ \\
\hline \multicolumn{12}{|c|}{ Changing and maintaining body position (d410 - d429) } \\
\hline$d 410$ & Changing basic body position & $x$ & $x$ & $x$ & $x$ & $x$ & $x$ & & & $x$ & \\
\hline d415 & Maintaining a body position & $x$ & $x$ & $x$ & $x$ & & & & & & \\
\hline$d 420$ & Transferring oneself & & $x$ & & & & $x$ & & & & \\
\hline \multicolumn{12}{|c|}{ Carrying, moving and handling objects (d430 - d449) } \\
\hline$d 430$ & Lifting and carrying objects & & & & & & & & & & \\
\hline d435 & Moving objects with lower extremities & & & & & & & & & & \\
\hline$d 440$ & Fine hand use & & & & & & & & & & \\
\hline d445 & Hand and arm use & & & & & & & & & & \\
\hline \multicolumn{12}{|c|}{ Walking and moving (d450 - d469) } \\
\hline$d 450$ & Walking & $x$ & $x$ & $x$ & $x$ & $x$ & $x$ & $x$ & $x$ & & $x$ \\
\hline d455 & Moving around & & $x$ & & & & $x$ & & & & \\
\hline$d 460$ & Moving around in different locations & & & & & & & & & & \\
\hline d465 & Moving around using equipment & $x$ & $x$ & $x$ & & $x$ & $x$ & & & & \\
\hline \multicolumn{12}{|c|}{ Moving around using transportation (d470 - d489) } \\
\hline$d 470$ & Using transportation & & & & & & & & & & \\
\hline d475 & Driving & & & & & & & & & & \\
\hline$d 480$ & Riding animals for transportation & & & & & & & & & & \\
\hline
\end{tabular}

The domain components (constructs) of each instrument are classified according to the domain "mobility" (Activities and Participation, Chapter 4) described in the World Health Organization's ICF. The ICF Mobility definition is: "Moving by changing body position or location or by transferring from one place to another, by carrying, moving or manipulating objects, by walking, running or climbing, and by using various forms of transportation"

Abbreviations: ICF International classification of functioning, disability and health (ICF), DEMMI De Morton mobility index, HABAM Hierarchical assessment of balance and mobility, POMA Performance oriented mobility assessment, SPPB Short physical performance battery, TUG Timed up and go test, BI Barthel index, FAC Functional ambulation categories, $5 \times C R T 5$ times chair rise test, 2minWT 2-min walk test 
For the retest sub-sample, the sample size was determined a priori and guided by the following three approximations: (1) For the main measure, the DEMMI, a minimum of 38 participants was needed based on the assumption of two occasions, a planning value of ICC = 0.92 reported by others [46] and the desired 95\% confidence interval (CI) with a width of 0.10 [47]. (2) The COnsensus-based Standards for the selection of health Measurement INstruments (COSMIN) group recommends at least 30, 50 or 100 participants for a reliability study to have a "fair", "good" or "excellent" sample size, respectively [2, 48]. (3) For measures of gait and sit-to-stand transfers, floor effects of approximately $50 \%$ were expected [11, 49-51]. To reach a "fair" sample size for such instruments subjected to large floor effects and missing values, we intended to re-assess at least 60 participants ( $n \geq 30$ after $50 \%$ drop-out).

\section{Measurement error: standard error of measurement}

For the continuous outcomes, the standard error of

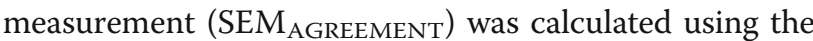
same variance components used for the ICC AGREEMENT $_{\text {AGR }}$ calculation. The SEM AGREEMENT was calculated using the square root of the variance between the two occasions and the error variance of the ICC $\mathrm{IAREEMENT}_{\text {[ }}$ [4].

For categorial measures, no parameters of measurement error can be calculated that quantify the measurement error in the units of measurement. To quantify agreement for the FAC, the percentage of measurements classified in the same FAC categories was calculated [52].

\section{Measurement error: limits of agreement/Bland and Altman plot}

The method of Bland and Altman was used to illustrate agreement between the baseline and retest measures of each instrument [5]. The 95\% limits of agreement require homoscedasticity and normally distributed differences [53]. A positive Kendall's tau ( $\tau$ ) correlation between the absolute differences and the corresponding means $>0.1$ was deemed to denote heteroscedasticity [54]. In case of heteroscedastic data, the following formula was used to calculate the limits of agreement: $2 \mathrm{X} \frac{\left(10^{a}-1\right)}{\left(10^{a}+1\right)}$ and $+2 \mathrm{X} \frac{\left(10^{a}-1\right)}{\left(10^{a}+1\right)}$, where $a=95 \%$ limits of agreement of the $10 \log$ transformed data, and $\mathrm{X}=$ the mean score [55]. We added bar charts for frequencies of differences to allow better interpretation.

\section{Measurement error: minimal detectable change}

The minimal detectable change (MDC) with 90 and 95\% confidence, a quantification of absolute agreement, was calculated based on the test-retest reliability data as $\mathrm{MDC}_{90}=$ $1.64 * \sqrt{2} * \mathrm{SEM}_{\mathrm{AGREEMENT}}$ and $\mathrm{MDC}_{95}=1.96 * \sqrt{2} * \mathrm{SEM}_{\mathrm{AGREE}-}$ MENT, respectively. The $\mathrm{MDC}_{95}\left(\mathrm{MDC}_{90}\right)$ is defined as the minimal amount of change that needs to occur between repeated assessments in an individual to exceed, with 95\% (90\%) confidence, the error of the measurement [56]. For all scales that consist of whole numbers only (DEMMI, HABAM, POMA, SPPB and Barthel Index mobility subscale), MDC values were rounded up to whole numbers.

\section{Results}

The baseline sample included 153 participants with cognitive impairment, of which 65 stable/unchanged participants were re-assessed within 1 day (participant flow: Fig. 1; admission characteristics: Table 2).

Twenty-nine percent of participants presented with a moderate cognitive impairment, and $71 \%$ presented with a mild cognitive impairment. Thirty-seven percent of participants were diagnosed with dementia, while $17 \%$ were diagnosed with delirium. The mean time span between the cognitive assessment and the study assessments was $2.6 \pm 1.2$ (range: 0-5) days. Approximately one out of two participants (49\%) reported a fall and its consequences as the main reason for their hospital admission.

Most participants ( $n=38,58 \%)$ were unable to walk or needed some kind of assistance for walking. Of the 65 participants, 30 (46\%) were not physically able to perform the 2-min walk test and the gait speed measure over $4 \mathrm{~m}$. These participants were generally either not able to walk at all, or they required assistance from one or more people to walk. The $5 \mathrm{xCRT}$ test could be evaluated in only $16(25 \%)$ participants due to insufficient sit-to-stand transfer abilities, mainly based on limited lower limb strength, in the other 49 participants (75\%). These 49 participants were not able to complete a sit to stand transfer without arms during the DEMMI administration (item \#6). The TUG could not be assessed in 32 (49\%) participants at baseline due to physical impairment $(n=31)$ and limited understanding of the test instructions $(n=1)$.

Reliability assessments were performed in the very early phase after hospital admission, with 3 days on average and within 5 days for every participant. The retest assessment was performed $218 \pm 86$ (range: 60-405) minutes after the first assessment. The time span between both assessments was $\leq 2 \mathrm{~h}$ for 11 participants (17\%), between 2.25 and $4 \mathrm{~h}$ for 30 participants (46\%), between 4.25 and $6 \mathrm{~h}$ for 22 participants (34\%) and $>6 \mathrm{~h}$ for 2 participants $(3 \%)$.

\section{Reliability}

\section{Test-retest reliability}

Data on test-retest reliability are shown in Table 3 and in the Additional file 2 (instrument subscales). There were statistically significant mean test-retest 


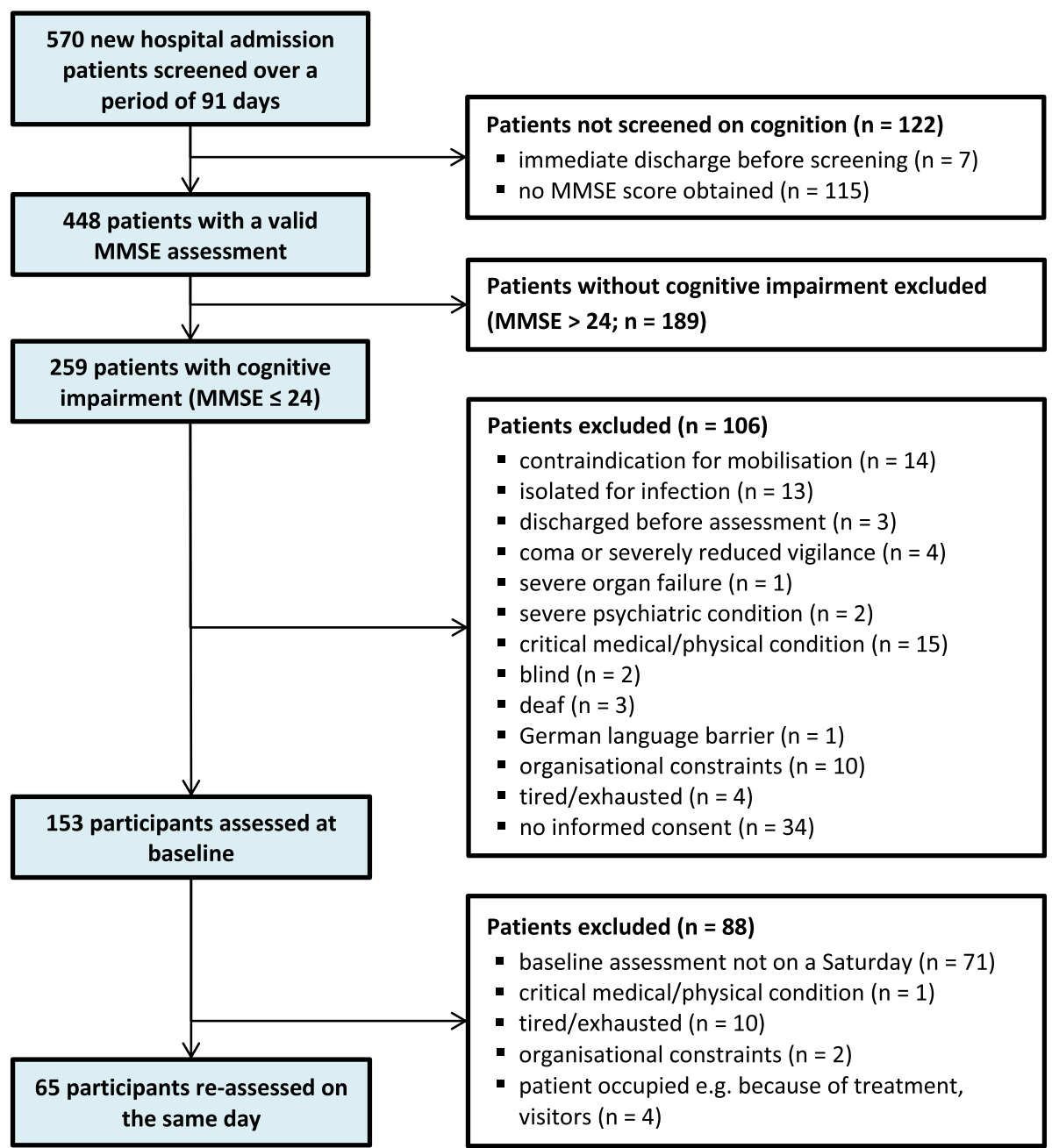

Fig. 1 Flow chart of study participants (MMSE = Mini-Mental State Examination)

differences for some instruments, varying between 4 and $14 \%$ of the baseline score. In all measures, patients performed better in the retest than in the baseline measure. There was no considerable variance due to systematic differences over time in any assessment $\left(\sigma^{2}{ }_{o}<1\right)$ except for the 2-min walk test $\left(\sigma^{2}{ }_{o}=8.2\right)$.

The $\mathrm{ICC}_{\text {AGREEMENT }}$ was above 0.9 in all outcomes except for the gait speed measure (ICC $=0.86$; 95\% CI: 0.750.93 ) and the $5 x \mathrm{xCRT}(\mathrm{ICC}=0.72$; 95\% CI: 0.38-0.89).

For the FAC, test-retest reliability was $\mathrm{K}=0.97(95 \%$ CI: 0.94-0.99; Table 4). Kappa values for the individual Barthel Index mobility subscale items were as follows: transfer $\mathrm{K}=0.90$, mobility $\mathrm{K}=0.96$ and stairs $\mathrm{K}=0.87$ (Additional file 3). There were no significant differences in reliability of test scores between sub-groups of men and women, indicated by overlapping $95 \%$ CI of the ICC and $\mathrm{k}$ values, except for the Barthel Index mobility subscale and the FAC (Additional file 4).

\section{Measurement error: standard error of measurement}

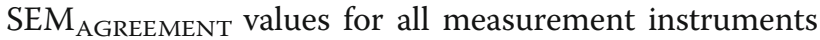
and subscales are given in Table 3 and the Additional file 2 , respectively. The SEM relative to the scale range was between 2.3\% (DEMMI) and 5.6\% (SPPB). The SEM relative to the mean value of the first measure was between 5.9\% (DEMMI) and 23.9\% (SPPB).

Agreement in FAC scores between two measures was 92\% (Table 4). Agreement of the Barthel Index mobility subscale items was between 58 and $62 \%$ (Additional file 3).

\section{Measurement error: limits of agreement/Bland and Altman plot}

The Bland and Altman plots of all measurement instruments are presented in Additional file 5. The 95\% absolute limits of agreement for each instrument are listed in Table 3 and Additional file 2. 
Table 2 Characteristics of participants $(n=65)$

\begin{tabular}{|c|c|}
\hline Characteristic & Value \\
\hline Age, years & $82 \pm 7(71-97)$ \\
\hline Gender: male/female, n (\%) & $29 / 36(45 / 55)$ \\
\hline $\begin{array}{l}\text { Pre-clinical living situation: } \\
\text { home alone/home with family or } \\
\text { relatives/ institutionalized, } n(\%)\end{array}$ & $34 / 29 / 2(52 / 45 / 3)$ \\
\hline $\begin{array}{l}\text { Time between admission and } \\
\text { assessment, days }\end{array}$ & $2.9 \pm 1.2(1-5)$ \\
\hline $\begin{array}{l}\text { Total length of stay on the acute } \\
\text { ward, days }\end{array}$ & $19 \pm 10(7-64)$ \\
\hline \multicolumn{2}{|c|}{ Primary diagnosis according to ICD-10 categories } \\
\hline IX Circulatory, n (\%) & $11(17)$ \\
\hline X Respiratory, n (\%) & $5(8)$ \\
\hline XIII Musculoskeletal, n (\%) & $5(8)$ \\
\hline $\begin{array}{l}\text { XVIII Symptoms, signs and } \\
\text { abnormal clinical and laboratory } \\
\text { findings, not elsewhere classified, n (\%) }\end{array}$ & $7(11)$ \\
\hline $\begin{array}{l}\text { XIX Injury, poisoning and certain } \\
\text { other consequences of external causes }\end{array}$ & $24(37)$ \\
\hline Other, n (\%) & $13(20)$ \\
\hline
\end{tabular}

Potential reasons for a cognitive impairment reported in the medical chart (diagnosis, symptom, medical sign; double-counts due to multi-morbidity)

$\begin{array}{ll}\text { None reported, } \mathrm{n}(\%) & 21(32) \\ \text { Alzheimer's dementia, } \mathrm{n}(\%) & 3(5) \\ \text { Vascular dementia, n (\%) } & 6(9) \\ \text { Dementia, not specified, n (\%) } & 15(23) \\ \text { Parkinson's disease, n (\%) } & 4(6) \\ \text { Stroke, n (\%) } & 8(12) \\ \text { Depression, n (\%) } & 15(23) \\ \text { Delir, } \mathrm{n}(\%) & 11(17) \\ \text { Other (psychosis, alcohol } & 3(5) \\ \text { abuse), n (\%) } & \\ \text { In-hospital walking aid } & \\ \text { Wheeled-walker/rollator, n (\%) } & 23(35) \\ \text { None, n (\%) } & 7(11) \\ \text { Cane/single crutch, n (\%) } & 7(11) \\ \text { Other, n (\%) } & 2(3) \\ \text { Non-ambulatory (wheelchair), n (\%) } & 26(40) \\ \text { Ambulation } & \end{array}$

Table 2 Characteristics of participants $(n=65)$ (Continued)

\begin{tabular}{|c|c|}
\hline Characteristic & Value \\
\hline $\begin{array}{l}\text { Moderate cognitive impairment, } \\
10-18 \text { points, } n(\%)\end{array}$ & $19(29)$ \\
\hline $\begin{array}{l}\text { Mild cognitive impairment, } \\
19-24 \text { points, } n(\%)\end{array}$ & $46(71)$ \\
\hline Mean score, points & $20 \pm 4(10-24)$ \\
\hline Median score, points & $21(18-23)$ \\
\hline \multicolumn{2}{|l|}{ Clock Drawing Test, 1-6 points } \\
\hline Unsuspicious: 1-2 points, n (\%) & $8(12)$ \\
\hline Suspicious: 3-6 points, n (\%) & $40(62)$ \\
\hline Missing/not possible, n (\%) & $17(26)$ \\
\hline Mean score, points $(n=122)$ & $4.0 \pm 1.3(1-6)$ \\
\hline \multicolumn{2}{|l|}{$\begin{array}{l}\text { Geriatric Depression Scale short } \\
\text { form, } 0-15 \text { points }\end{array}$} \\
\hline Normal: 0-4 points, n (\%) & $30(46)$ \\
\hline Mildly depressive: 5-8 points, n (\%) & $17(26)$ \\
\hline $\begin{array}{l}\text { Moderately depressive: 9-11 } \\
\text { points, } \mathrm{n}(\%)\end{array}$ & $8(12)$ \\
\hline $\begin{array}{l}\text { Severely depressive: 12-15 } \\
\text { points, } \mathrm{n}(\%)\end{array}$ & $4(6)$ \\
\hline Missing/not possible, n (\%) & $1 / 5(2 / 8)$ \\
\hline Mean score, points $(n=59)$ & $5 \pm 3(0-13)$ \\
\hline
\end{tabular}

\section{Measurement error: minimal detectable change}

$\mathrm{MDC}_{90}$ and $\mathrm{MDC}_{95}$ values are given in Table 3 and Additional file 2 .

\section{Discussion}

The results indicate sufficient test-retest reliability for group-comparisons of the DEMMI, HABAM, POMA, SPPB, 2-min walk test, TUG, Barthel Index mobility subscale and FAC in older acute medical patients with cognitive impairment. Short-distance gait speed and chair rise measures seem insufficient $(\mathrm{ICC}<0.9)$ for monitoring individual changes over time. The clinical utility of the short- and long-distance walk tests, the TUG and the chair rise test seems further limited due to significant floor effects.

\section{Relative test-retest reliability}

The COSMIN group proposed ICC and values $\geq 0.7$ as indicators of acceptable reliability [44]. An ICC $\geq 0.7$ is deemed sufficient for group comparison, but for individual-level monitoring, the ICC should exceed 0.90 [45]. The ICC $_{\text {AGREEMENT }}$ was $\geq 0.90$ in all instruments except for the gait speed (0.86) and chair rise (0.72) measures. Thus, all instruments seem to have sufficient test-retest reliability (in terms of the consistency of 


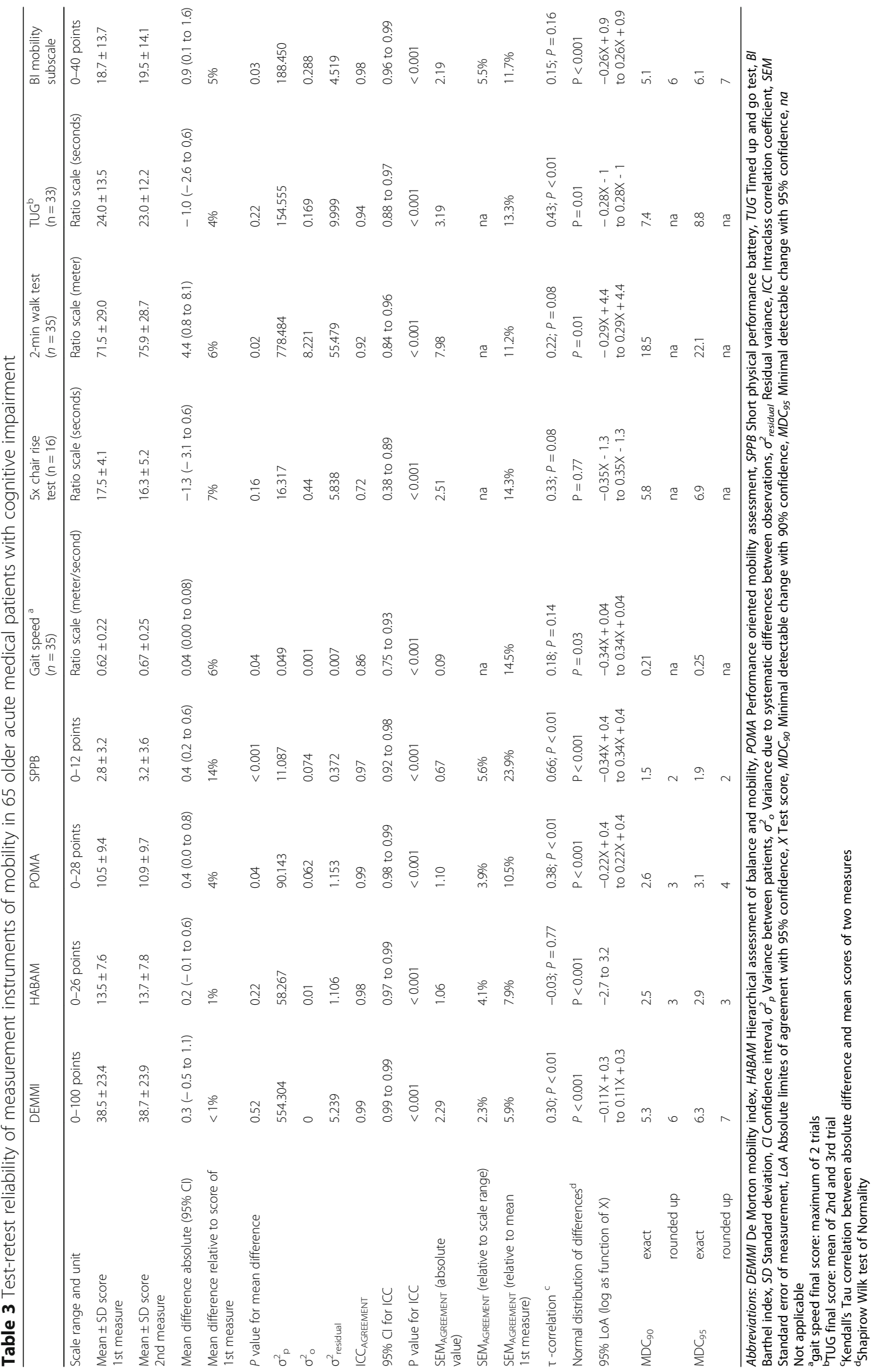


Table 4 Test-retest reliability of the Functional Ambulation Categories; $n=65$; kappa =0.97 (95\% Cl: 0.94-0.99); agreement $=92 \%$

\begin{tabular}{lllllllll}
\hline & \multicolumn{4}{c}{ Second measure scores } & & \multirow{2}{*}{$\begin{array}{l}\text { Observed proportion } \\
\text { of agreement }(95 \% \mathrm{Cl})\end{array}$} \\
\cline { 2 - 7 } & & 0 & 1 & 2 & 3 & 4 & 5 & \\
\hline First measure & 0 & 27 & 0 & 0 & 0 & 0 & 0 & $100 \%(85-100)$ \\
scores & 1 & 0 & 3 & 0 & 0 & 0 & 0 & $100 \%(31-100)$ \\
& 2 & 0 & 0 & 0 & 0 & 0 & 0 & na \\
& 3 & 0 & 0 & 0 & 8 & 0 & 0 & $100 \%(60-100)$ \\
& 4 & 0 & 0 & 0 & 0 & 16 & 5 & $76 \%(52-91)$ \\
& 5 & 0 & 0 & 0 & 0 & 0 & 6 & $55 \%(25-82)$ \\
\hline
\end{tabular}

Cl Confidence interval, na Not applicable

within-group position), and all but the two measures mentioned seem to be suitable for the individual-level assessment of mobility over time in older acute medical patients with cognitive impairment. The results also indicate that multi-component instruments have better test-retest reliability than single-component measures.

The comparison of reliability approximations found in the present study with existing evidence is limited due to the small number of reliability studies performed with older adults with dementia and other cognitive impairment. However, there is some evidence of the test-retest reliability of physical performance measures in older (acute medical) patients with dementia, which can serve as a reference [11-13, 15-18, 20-22]. In general, and in agreement with the present study, these studies indicate sufficient test-retest reliability for most instruments, but the measurement error seems to be large and to limit the monitoring of clinically relevant intra-individual changes $[17,18,20]$. In the following, we will discuss the relative test-retest reliability of each measurement instrument under study.

\section{Multi-component measures of mobility}

The test-retest reliability of the DEMMI and HABAM has not been examined in a well-defined group of older people with cognitive impairment before. The test-retest reliability of the DEMMI (ICC $=0.99$ ) is very high and comparable to the intra-rater reliability reported by other authors (0.86 to 0.98$)[46,57]$. In addition, the HABAM ICC value of 0.98 found in the present sample is comparable to the test-retest reliability found in two samples of mixed geriatric inpatients, assessed within one $(n=30 ; \mathrm{ICC}=0.99$ [57]) or two ( $n=63$; ICC $=0.91$ [58]) hospital days.

There is also very limited evidence on the reliability of the POMA in older people with cognitive impairment. Sterke et al. [10] reported excellent test-retest reliability for POMA total and subscale scores (ICC $=0.88$ to 0.97 ) in 11 nursing home residents with moderate to severe dementia, a result comparable to our findings (ICC $=0.97$ to 0.99 ).

We applied the TUG with 33 participants and found high test-retest reliability (ICC $=0.92$ ). There is conflicting evidence for the TUG, with reliability reports ranging from 0.56 [11], 0.72 [14], 0.76 [15], 0.86 [17] and 0.58 to $0.96[16]$.

No reliability studies have been performed for the mobility subscale of the Barthel Index in older people with cognitive impairment or dementia. The ICC of 0.98 in the present study is comparable to the ICC values between 0.94 and 0.96 reported for the total Barthel Index in rehabilitation patients with stroke found in a systematic review [59].

There is scarce evidence on the reliability of the SPPB in older people with cognitive impairment. Fox et al. [17] reported an ICC of 0.88 for the SPPB in a small-scale pilot study with 11 older adults with dementia who lived in residential aged care facilities. The reliability estimation found in the present study (ICC $=0.97 ; 95 \% \mathrm{CI}$ : 0.92-0.98) is based on a much larger sample $(n=65)$ recruited in a different setting.

\section{Single-component measures of mobility}

For short-distance gait speed measures, some authors have reported inconsistent reliability estimations in older people with dementia, ranging from insufficient (0.57 to 0.68$)$ [ 16 , $17]$ to excellent $(0.95$ to 0.97$)[16,18,19]$. Reliability estimations of gait speed test scores seem to be influenced by the research protocol and the method of gait speed assessment $[60,61]$. Based on our findings, gait speed can be assessed reliably for group-comparisons $(\mathrm{ICC}=0.86$ ) in older acute medical patients with mild to moderate cognitive impairment if gait speed is assessed according to the methods used in this study: standing start, usual/comfortable pace, 4-m distance and the shorter time of two trials. However, short-distance gait speed measures seem to be insufficiently reliable for measuring intra-individual changes over time in this population.

We applied the 2-min walk test, a shorter version of the 6-min walk test, to assess mobility and walking endurance and found acceptable test-retest reliability (ICC $=0.92$ ) in 35 ambulatory participants. There is evidence of reliability for the 6-min walk test only for older people with dementia. Depending on the time interval between two measures, the ICC was 0.99 (test-rest: $30-60 \mathrm{~min}$; $n=33$ ) [18] and 0.76 to 0.90 (intra-day and 1 week apart; $n=33)[16]$.

The test-retest reliability for timed chair rise tests has been reported to be between 0.79 and 0.96 [15, 17, 20, 22] The ICC of 0.72 (95\% CI: $0.38-0.89 ; n=16$ ) in the present study may deviate because of the small sample size.

To the best of our knowledge, there is no evidence for the reliability of the FAC in older people with cognitive impairment. We found a very high test-retest reliability $(\mathrm{k}$ $=0.97)$, which is comparable to the excellent test-retest $(\mathrm{K}$ $=0.95)$ and inter-rater $(\mathrm{K}=0.91)$ reliability reported for patients with acute stroke [62]. 


\section{Measurement error}

Measurement error can be expressed as the SEM, the limits of agreement and MDC scores. These absolute reliability scores are easy to interpret because they are expressed in the same units as the original measure. The SEM (as \% value) relative to the scale range and to the mean of the first measure allow for direct comparison of the measurement error between the measurement instruments examined in this study.

The results of our study confirm previous findings of rather large measurement error in mobility measures used with older people with dementia [17, 18, 20, 63]. The DEMMI has the smallest relative SEM and the SPPB has the largest SEM.

The limits of agreement increase by at least $20 \%$ for every retest score in all instruments except the DEMMI (11\%) and the HABAM, for which the limits of agreement are -2.7 to 3.2 points, which is $11 \%(0.5 * 5.9$ points/26 points*100\%) of the total scale range. For the $\mathrm{SPPB}, 5 \mathrm{xCRT}$ and gait speed measures, the limits of agreement increase by $>30 \%$. These large limits of agreement and MDC scores established for most scales limit the applicability in measuring change over time in older people with cognitive impairment for several reasons: First, a change in mobility needs to be very large to exceed the measurement error. Second, the measurement error may be larger than the minimal important change, including small but clinically relevant changes. For example, the $\mathrm{MDC}_{90}$ for gait speed is $0.21 \mathrm{~m} / \mathrm{s}$ and exceeds the median minimal important change of 0.14 $\mathrm{m} / \mathrm{s}$ reported in a systematic review [64]. For the SPPB, the small meaningful change and the substantial change have been reported to be 0.27 to 0.55 points and 0.99 to 1.34 points, respectively [65]. Both values are lower than the $\mathrm{MDC}_{90}$ of 1.5 points found in the present study. Clinicians and researchers should consider the substantial measurement error in all scales but the DEMMI and the HABAM.

Heteroscedasticity in most data indicates a larger measurement error in higher test scores. For example, the test-retest limits of agreement for a patient with a DEMMI score of 30 points ( -3.0 to 3.6 ) are much lower than for a patient with a score of 70 points ( -7.4 to 8.0$)$. The MDC values and limits of agreement presented in this study can be used to decide if a change score of an individual older person with cognitive impairment is likely to be measurement error or true change.

\section{Strengths and limitations}

This study provides a comprehensive head-to-head comparison of the test-retest reliability of a broad set of commonly used performance-based mobility measures in older people, including instrument subscales. The selection was based on psychometric evidence, clinical feasibility and awareness [12, 13, 23, 24, 26, 27, 66-68]. Our study includes the most frequently applied instruments such as TUG, SPPB and gait speed [13, 68].

A further strength of this study is the sufficiently large [48] and consecutive sample of 65 participants, which can be judged as "good" according to the COSMIN criteria $[2,48]$. However, due to significant floor effects, the sample size decreased partly but was still over the minimally acceptable threshold of $n \geq 30$ for the timed walking tests [44].

Participants were assessed within 1 day. We aimed to include only "unchanged/stable" older people according to the definition of reliability and the recommendations on reliability study methods [2, 4]. Even though we have tried to validate the participants' statements, the reliability of asking cognitively impaired persons about the stability of their status is not known. Further, in clinical care, it is highly unlikely that mobility is assessed twice on the same day, although frequent measurements of mobility seem worthwhile [69]. A longer interval between both study measures (e.g. $24 \mathrm{~h}$ or 3 days) would have been more representative of the procedures currently applied in clinical practice. In that case, however, it would have been very unlikely that unchanged/stable participants would be included, since short-time intra-individual changes in physical performance are quite common in critically ill, older acute medical patients with cognitive impairment. In a study by Hatheway et al. [70], $28 \%$ of the included older hospital patients improved their mobility and balance (HABAM) within the first $48 \mathrm{~h}$. In the present study, we observed statistically significant changes of 4 to $14 \%$ in mobility performance within 1 day according to some instruments, such as the SPPB and 2-min walk test. While the individual results may still be subject to participant fatigue, all statistically significant changes observed in the present study indicate improvements in mobility. Thus, fatigue does not seem to have significantly affected overall test performances. These changes may be based on altered coordination, motor control and other facets of biological variability overlapping with fatigue. Since the DEMMI was the first measure administered, it is less susceptible for participant fatigue during an assessment session. While our results indicate otherwise, it cannot be ruled out that reliability estimations of the measurement instruments applied at the end of each session have been affected more strongly by fatigue than the DEMMI.

A further limitation of this study is that we cannot formally explain cognitive impairment based on a medical diagnosis in all participants. A diagnosis of dementia was not documented for $63 \%$ of the participants. Since cognitive impairment may be based on other pathologies or on fluctuating acute changes in mental status, such as 
stroke or delirium, this result is not surprising. The diagnosis of dementia can be a time-consuming process that needs longitudinal observation of the course and features of cognitive decline. Usually, it needs to be supported by reports of relatives/caregivers. This may be difficult in busy acute hospitals, where most patients stay for a short time only.

Dementia and delirium are frequently unrecognised and unreported even when present, and many clinicians find it hard to distinguish between the two disorders, especially since a great deal of overlap exists between these syndromes $[71,72]$. In the present study, further misclassification may be based on participants with depression, but intact cognition, who scored low on the MMSE [72]. Another bias may result from the time span between the cognitive assessment and the study assessment of $2.6 \pm 1.2$ days. Since cognitive function may be fluctuating in this acute population, especially in patients with delirium, the level of cognitive function might have changed within this period of time. A more detailed and instant psychiatric review of study participants would have helped to better select and describe the study sample.

Test results of performance-based measures in older people with cognitive impairment can be influenced by the patient's adequate motivation and attention during testing, among others [9]. These conditions usually depend on the handling, communication and experience of the assessor. The external validity of these reliability estimations might be limited by the fact that the tests were performed by a trained assessor with a quite high level of work and instrument routine. However, the test-retest reliability of other assessors should be comparable if the same strict learning procedure is followed and if the instrument is applied by the same rater at both occasions. All measures are well established and commonly used by clinicians working with older people. Furthermore, data were collected in a single hospital by one single rater only. The rater was not blinded towards the participants' levels of cognitive impairment and the test scores of the first assessment session, which may be a major limitation of the study.

\section{Conclusions and implications for practice}

All examined instruments show sufficient relative test-retest reliability for group comparison. Hence, these tests seem suitable for cross-sectional and interventional studies of older acute medical patients with mild to moderate cognitive impairment. For individual-level monitoring of change over time, the test-retest reliability of the short-distance gait speed and chair rise measures is insufficient $(\mathrm{ICC}<0.9)$ for this purpose in this population. The clinical application of gait speed and chair rise tests should be critically considered in older acute medical patients, since ambulation and sit-to-stand transfers are applicable to a limited number of higherfunctioning patients only. This limitation was also observed in the TUG and the 2-min walk test.

For the DEMMI, HABAM, POMA, TUG, SPPB, FAC, 2-min walk test and the mobility subscale of the Barthel Index, the relative reliability seems sufficient for longitudinal individual-level assessment of mobility in older people with cognitive impairment. However, MDC values and absolute reliability estimations indicate rather large measurement error for many of these instruments. This may seriously limit the detection of clinically meaningful changes over time. Clinicians and researchers should consider the substantial measurement error in most scales. The DEMMI (11\%) and the HABAM (11\%) were the only instruments with a measurement error (95\% limits of agreement) below $20 \%$.

\section{Additional files}

Additional file 1: Detailed description of the assessment procedure and all measurement instruments and their subscales. (PDF 395 kb)

Additional file 2: Test-retest reliability of subscales of measurement instruments of mobility in 65 older acute medical patients with cognitive impairment. (PDF $95.6 \mathrm{~kb}$ )

Additional file 3: Agreement of the Barthel Index mobility subscale items. (PDF $352 \mathrm{~kb}$ )

Additional file 4: Test-retest reliability of measurement instruments of mobility by gender. (PDF $113 \mathrm{~kb}$ )

Additional file 5: Bland and Altman plots of measurement instruments of mobility, including the corresponding subscales (Figures A-N). (PDF 309 kb)

\section{Abbreviations \\ 5xCRT: 5-times chair rise test; Cl: Confidence interval; COSMIN: COnsensus- based Standards for the selection of health Measurement Instruments; DEMMI: De Morton Mobility Index; FAC: Functional Ambulation Categories; HABAM: Hierarchical Assessment of Balance and Mobility; ICC: Intraclass correlation coefficient; ICF: International Classification of Functioning, Disability and Health; MDC: Minimal detectable change; MMSE: Mini-Mental State Examination; POMA: Performance Oriented Mobility Assessment; SEM: Standard error of measurement; SPPB: Short Physical Performance Battery; TUG: Timed up and go test}

\section{Acknowledgements}

The authors thank all participants for taking part in this study. We further acknowledge the support of the physiotherapy, occupational therapy, nursing and medical staff of the St. Marien-Hospital in Cologne.

\section{Funding}

This research received no specific grant from any funding agency in the public, commercial or not-for-profit sectors.

\section{Availability of data and materials}

Data can be obtained from the corresponding author upon reasonable request.

\section{Authors' contributions}

Study concept and design: TB, RJS, CG. Acquisition and analysis of data: TB. Interpretation of data: TB, CG, CT. Drafting the manuscript: TB. Manuscript revision for important intellectual content: $C T$, RJS, CG. Final approval of the version to be published: $T B, C T, R J S, C G$. 


\section{Ethics approval and consent to participate}

The study was approved by the Ethical Review Board of the University of Cologne. Ongoing, written informed consent was provided by all participants. Guardian informed consent was approved if necessary.

\section{Consent for publication}

Not applicable.

\section{Competing interests}

The authors declare that they have no competing interests.

\section{Publisher's Note}

Springer Nature remains neutral with regard to jurisdictional claims in published maps and institutional affiliations.

\section{Author details}

${ }^{1}$ Department of Applied Health Sciences, Division of Physiotherapy, Hochschule für Gesundheit (University of Applied Sciences), Gesundheitscampus 6-8, 44801 Bochum, Germany. ${ }^{2}$ Faculty of Sports Science, Training and Exercise Science, Ruhr-University Bochum, Bochum, Germany. ${ }^{3}$ Department of Geriatric Medicine, St. Marien-Hospital, Kunibertskloster 11-13, 50668 Cologne, Germany.

\section{Received: 23 July 2018 Accepted: 14 January 2019}

\section{Published online: 23 January 2019}

\section{References}

1. World Health Organization. International classification of functioning, disability and health: ICF. Geneva: World Health Organization; 2001.

2. Mokkink LB, Terwee CB, Patrick DL, Alonso J, Stratford PW, Knol DL, et al. The COSMIN study reached international consensus on taxonomy, terminology, and definitions of measurement properties for health-related patient-reported outcomes. J Clin Epidemiol. 2010;63:737-45.

3. Carter R, Lubinsky J, Domholdt E. Rehabilitation research: principles and applications. 4th ed. Philadelphia, London: Saunders; 2010.

4. de Vet HCW, Terwee CB, Mokkink LB, Knol DL. Measurement in medicine: a practical guide. Cambridge: Cambridge University Press; 2011.

5. Bland JM, Altman DG. Statistical methods for assessing agreement between two methods of clinical measurement. Lancet. 1986;1:307-10.

6. Mukadam N, Sampson EL. A systematic review of the prevalence, associations and outcomes of dementia in older general hospital inpatients. Int Psychogeriatr. 2011;23:344-55.

7. Ryan DJ, O'Regan NA, Caoimh RO, Clare J, O'Connor M, Leonard M, et al. Delirium in an adult acute hospital population: predictors, prevalence and detection. BMJ Open. 2013;3:e001772.

8. Whittamore KH, Goldberg SE, Gladman JR, Le Bradshaw JRG, Harwood RH. The diagnosis, prevalence and outcome of delirium in a cohort of older people with mental health problems on general hospital wards. Int J Geriatr Psychiatry. 2014;29:32-40.

9. Hauer K, Oster P. Measuring functional performance in persons with dementia. J Am Geriatr Soc. 2008;56:949-50.

10. Sterke CS, Huisman SL, van Beeck EF, Looman CWN, van der Cammen TJM. Is the Tinetti performance oriented mobility assessment (POMA) a feasible and valid predictor of short-term fall risk in nursing home residents with dementia? Int Psychogeriatr. 2010;22:254-63.

11. Rockwood K, Awalt E, Carver D, MacKnight C. Feasibility and measurement properties of the functional reach and the timed up and go tests in the Canadian study of health and aging. J Gerontol A Biol Sci Med Sci. 2000;55:70-3.

12. Ross CM. Application and interpretation of functional outcome measures for testing individuals with cognitive impairment. Top Geriatr Rehabil. 2018;34: 13-35.

13. McGough EL, Lin S-Y, Belza B, Becofsky KM, Jones DL, Liu M, et al. A scoping review of physical performance outcome measures used in exercise interventions for older adults with Alzheimer disease and related dementias. J Geriatr Phys Ther. 2017. https://doi.org/10.1519/JPT.0000000000000159 [Epub ahead of print].

14. Muir-Hunter SW, Graham L, Montero OM. Reliability of the Berg balance scale as a clinical measure of balance in community-dwelling older adults with mild to moderate Alzheimer disease: a pilot study. Physiother Can. 2015;67:255-62.
15. Suttanon P, Hill KD, Dodd KJ, Said CM. Retest reliability of balance and mobility measurements in people with mild to moderate Alzheimer's disease. Int Psychogeriatr. 2011;23:1152-9.

16. Tappen RM, Roach KE, Buchner D, Barry C, Edelstein J. Reliability of physical performance measures in nursing home residents with Alzheimer's disease. J Gerontol A Biol Sci Med Sci. 1997:52:5.

17. Fox B, Henwood T, Neville C, Keogh J. Relative and absolute reliability of functional performance measures for adults with dementia living in residential aged care. Int Psychogeriatr. 2014;26:1659-67.

18. Ries JD, Echternach JL, Nof L, Gagnon BM. Test-retest reliability and minimal detectable change scores for the timed "up \& go" test, the six-minute walk test, and gait speed in people with Alzheimer disease. Phys Ther. 2009;89:569-79.

19. McGough EL, Logsdon RG, Kelly VE, Teri L. Functional mobility limitations and falls in assisted living residents with dementia: physical performance assessment and quantitative gait analysis. J Geriatr Phys Ther. 2013;36:78-86.

20. Blankevoort CG, van Heuvelen MJG, Scherder EJA. Reliability of six physical performance tests in older people with dementia. Phys Ther. 2013;93:69-78,

21. Telenius EW, Engedal K, Bergland A. Inter-rater reliability of the Berg balance scale, $30 \mathrm{~s}$ chair stand test and $6 \mathrm{~m}$ walking test, and construct validity of the Berg balance scale in nursing home residents with mild-to-moderate dementia. BMJ Open. 2015;5:e008321.

22. Thomas VS, Hageman PA. A preliminary study on the reliability of physical performance measures in older day-care center clients with dementia. Int Psychogeriatr. 2002;14:17-23.

23. de Morton NA, Berlowitz DJ, Keating JL. A systematic review of mobility instruments and their measurement properties for older acute medical patients. Health Qual Life Outcomes. 2008;6:44.

24. Soares Menezes KVR, Auger C, de Souza Menezes WR, Guerra RO. Instruments to evaluate mobility capacity of older adults during hospitalization: a systematic review. Arch Gerontol Geriatr. 2017;72:67-79.

25. Macknight C, Rockwood K. A hierarchical assessment of balance and mobility. Age Ageing. 1995;24:126-30.

26. Pavasini R, Guralnik J, Brown JC, Di Bari M, Cesari M, Landi F, et al. Short physical performance battery and all-cause mortality: systematic review and meta-analysis. BMC Med. 2016;14:215.

27. de Morton NA, Davidson M, Keating JL. The de Morton mobility index (DEMMI): an essential health index for an ageing world. Health Qual Life Outcomes. 2008;6:63.

28. Braun T, Grüneberg C, Thiel C, Schulz R-J. Measuring mobility in older hospital patients with cognitive impairment using the de Morton mobility index. BMC Geriatr. 2018;18:100.

29. von Elm E, Altman DG, Egger M, Pocock SJ, Gotzsche PC, Vandenbroucke $J P$. The Strengthening the reporting of observational studies in epidemiology (STROBE) statement: guidelines for reporting observational studies. J Clin Epidemiol. 2008;61:344-9.

30. Kottner J, Audige L, Brorson S, Donner A, Gajewski BJ, Hrobjartsson A, et al. Guidelines for reporting reliability and agreement studies (GRRAS) were proposed. J Clin Epidemiol. 2011;64:96-106.

31. Folstein MF, Folstein SE, McHugh PR. "Mini-mental state". A practical method for grading the cognitive state of patients for the clinician. J Psychiatr Res. 1975;12:189-98.

32. Shulman Kl. Clock-drawing: is it the ideal cognitive screening test? Int J Geriatr Psychiatry. 2000;15:548-61.

33. Yesavage JA, Sheikh JI. Geriatric depression scale (GDS) - recent evidence and development of a shorter version. Clin Gerontol. 2008;5:165-73.

34. Braun T, Schulz R-J, Reinke J, van Meeteren NL, de Morton NA, Davidson M, et al. Reliability and validity of the German translation of the de Morton mobility index (DEMMI) performed by physiotherapists in patients admitted to a sub-acute inpatient geriatric rehabilitation hospital. BMC Geriatr. 2015;15:1660.

35. MacKnight C, Rockwood K. Rasch analysis of the hierarchical assessment of balance and mobility (HABAM). J Clin Epidemiol. 2000;53:1242-7.

36. Braun T, Rieckmann A, Grüneberg C, Marks D, Thiel C. Hierarchical assessment of balance and mobility - German translation and cross-cultural adaptation. Z Gerontol Geriatr. 2016;49:386-97.

37. Tinetti ME. Performance-oriented assessment of mobility problems in elderly patients. J Am Geriatr Soc. 1986;34:119-26.

38. Guralnik JM, Simonsick EM, Ferrucci L, Glynn RJ, Berkman LF, Blazer DG, et al. A short physical performance battery assessing lower extremity function: association with self-reported disability and prediction of mortality and nursing home admission. J Gerontol. 1994;49:85-94.

39. Pin TW. Psychometric properties of 2-minute walk test: a systematic review. Arch Phys Med Rehabil. 2014;95:1759-75. 
40. Podsiadlo D, Richardson S. The timed "up \& go": a test of basic functional mobility for frail elderly persons. J Am Geriatr Soc. 1991;39:142-8.

41. Mahoney FI, Barthel DW. Functional evaluation: the Barthel index. Md State Med J. 1965;14:61-5.

42. Holden MK, Gill KM, Magliozzi MR, Nathan J, Piehl-Baker L. Clinical gait assessment in the neurologically impaired. Reliability and meaningfulness. Phys Ther. 1984;64:35-40.

43. Mudge S, Stott NS. Outcome measures to assess walking ability following stroke: a systematic review of the literature. Physiotherapy. 2007;93:189-200.

44. Terwee CB, Bot SDM, de Boer MR, van der Windt DAWM, Knol DL, Dekker J, et al. Quality criteria were proposed for measurement properties of health status questionnaires. J Clin Epidemiol. 2007;60:34-42.

45. Scientific Advisory Committee of the Medical Outcomes Trust. Assessing health status and quality-of-life instruments: attributes and review criteria. Qual Life Res. 2002;11:193-205.

46. de Morton N, Davidson M, Keating JL. Reliability of the de Morton mobility index (DEMMI) in an older acute medical population. Physiother Res Int. 2010;16:159-69.

47. Bonett DG. Sample size requirements for estimating intraclass correlations with desired precision. Stat Med. 2002;21:1331-5.

48. Terwee CB, Mokkink LB, Knol DL, Ostelo RWJG, Bouter LM, de Vet HCW. Rating the methodological quality in systematic reviews of studies on measurement properties: a scoring system for the COSMIN checklist. Qual Life Res. 2012;21:651-7.

49. Dasenbrock L, Berg T, Lurz S, Beimforde E, Diekmann R, Sobotka F, Bauer JM. The De Morton mobility index for evaluation of early geriatric rehabilitation. Z Gerontol Geriatr. 2016;49:398-404

50. Gan N, Large J, Basic D, Jennings N. The timed up and go test does not predict length of stay on an acute geriatric ward. Aust J Physiother. 2006;52:141-4.

51. Braun T, Schulz R-J, Hoffmann M, Reinke J, Tofaute L, Urner C, et al. German version of the de Morton mobility index. First clinical results from the process of the cross-cultural adaptation. Z Gerontol Geriatr. 2015;48:154-63.

52. de Vet HCW, Mokkink LB, Terwee CB, Hoekstra OS, Knol DL. Clinicians are right not to like Cohen's kappa. BMJ. 2013;346:f2125.

53. Altman DG, Bland JM. Measurement in medicine: the analysis of method comparison studies. Statistician. 1983;32:307-17.

54. Brehm MA, Scholtes VA, Dallmeijer AJ, Twisk JW, Harlaar J. The importance of addressing heteroscedasticity in the reliability analysis of ratio-scaled variables: an example based on walking energy-cost measurements. Dev Med Child Neurol. 2012;54:267-73.

55. Euser AM, Dekker FW, Le Cessie S. A practical approach to Bland-Altman plots and variation coefficients for log transformed variables. J Clin Epidemiol. 2008;61:978-82.

56. Stratford PW, Binkley JM, Riddle DL. Health status measures: strategies and analytic methods for assessing change scores. Phys Ther. 1996;76:1109-23.

57. Braun T, Grüneberg C, Coppers A, Tofaute L, Thiel C. Comparison of the de Morton mobility index and hierarchical assessment of balance and mobility in older acute medical patients. J Rehabil Med. 2018;50:292-301.

58. Rockwood K, Rockwood MRH, Andrew MK, Mitnitski A. Reliability of the hierarchical assessment of balance and mobility in frail older adults. J Am Geriatr Soc. 2008;56:1213-7.

59. Duffy L, Gajree S, Langhorne P, Stott DJ, Quinn TJ. Reliability (inter-rater agreement) of the Barthel index for assessment of stroke survivors: systematic review and meta-analysis. Stroke. 2013;44:462-8.

60. Graham JE, Ostir GV, Fisher SR, Ottenbacher KJ. Assessing walking speed in clinical research: a systematic review. J Eval Clin Pract. 2008;14:552-62.

61. Sustakoski A, Perera S, Vanswearingen JM, Studenski SA, Brach JS. The impact of testing protocol on recorded gait speed. Gait Posture. 2015;41: 329-31.

62. Mehrholz J, Wagner K, Rutte K, Meissner D, Pohl M. Predictive validity and responsiveness of the functional ambulation category in hemiparetic patients after stroke. Arch Phys Med Rehabil. 2007;88:1314-9.

63. van lersel MB, Munneke M, Esselink RAJ, Benraad CEM, Olde Rikkert MGM. Gait velocity and the timed-up-and-go test were sensitive to changes in mobility in frail elderly patients. J Clin Epidemiol. 2008;61:186-91.

64. Bohannon RW, Glenney SS. Minimal clinically important difference for change in comfortable gait speed of adults with pathology: a systematic review. J Eval Clin Pract. 2014;20:295-300.

65. Perera S, Mody SH, Woodman RC, Studenski SA. Meaningful change and responsiveness in common physical performance measures in older adults. J Am Geriatr Soc. 2006;54:743-9.
66. Davenport SJ, Paynter S, de Morton NA. What instruments have been used to assess the mobility of community-dwelling older adults? Phys Ther Rev. 2008;13:345-54

67. Chung J, Demiris G, Thompson HJ. Instruments to assess mobility limitation in community-dwelling older adults: a systematic review. J Aging Phys Act. 2015;23:298-313.

68. Bossers WJR, van der Woude LHV, Boersma F, Scherder EJA, van Heuvelen MJG. Recommended measures for the assessment of cognitive and physical performance in older patients with dementia: a systematic review. Dement Geriatr Cogn Dis Extra. 2012;2:589-609.

69. Hubbard RE, Eeles EMP, Rockwood MRH, Fallah N, Ross E, Mitnitski A, Rockwood K. Assessing balance and mobility to track illness and recovery in older inpatients. J Gen Intern Med. 2011;26:1471-8.

70. Hatheway OL, Mitnitski A, Rockwood K. Frailty affects the initial treatment response and time to recovery of mobility in acutely ill older adults admitted to hospital. Age Ageing. 2017:46:920-5.

71. Fong TG, Davis D, Growdon ME, Albuquerque A, Inouye SK. The interface between delirium and dementia in elderly adults. Lancet Neurol. 2015;14: 823-32.

72. Downing LJ, Caprio TV, Lyness JM. Geriatric psychiatry review: differential diagnosis and treatment of the 3 D's - delirium, dementia, and depression. Curr Psychiatry Rep. 2013:15:365.

\section{Ready to submit your research? Choose BMC and benefit from:}

- fast, convenient online submission

- thorough peer review by experienced researchers in your field

- rapid publication on acceptance

- support for research data, including large and complex data types

- gold Open Access which fosters wider collaboration and increased citations

- maximum visibility for your research: over $100 \mathrm{M}$ website views per year

At $\mathrm{BMC}$, research is always in progress.

Learn more biomedcentral.com/submissions 